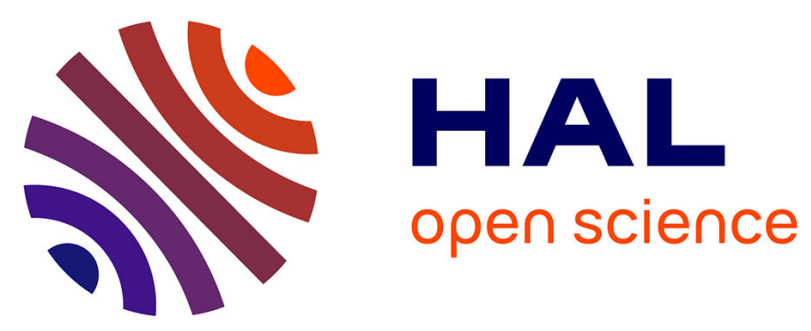

\title{
Properties and Alkaline Stability of Composite Anion Conducting Ionomers Based on Poly(phenylene oxide) Grafted with DABCO and Mg/Al Lamellar Double Hydroxide
}

L. Pasquini, R.-A Becerra-Arciniegas, R. Narducci, E. Sgreccia, Vincent Gressel, Philippe Knauth

\section{To cite this version:}

L. Pasquini, R.-A Becerra-Arciniegas, R. Narducci, E. Sgreccia, Vincent Gressel, et al.. Properties and Alkaline Stability of Composite Anion Conducting Ionomers Based on Poly(phenylene oxide) Grafted with DABCO and Mg/Al Lamellar Double Hydroxide. ChemElectroChem, 2020, 7 (13), pp.2917-2924. 10.1002/celc.202000523 . hal-03162027

\section{HAL Id: hal-03162027 \\ https://hal-amu.archives-ouvertes.fr/hal-03162027}

Submitted on 31 Mar 2021

HAL is a multi-disciplinary open access archive for the deposit and dissemination of scientific research documents, whether they are published or not. The documents may come from teaching and research institutions in France or abroad, or from public or private research centers.
L'archive ouverte pluridisciplinaire HAL, est destinée au dépôt et à la diffusion de documents scientifiques de niveau recherche, publiés ou non, émanant des établissements d'enseignement et de recherche français ou étrangers, des laboratoires publics ou privés. 
Properties and alkaline stability of composite anion conducting ionomers based on poly(phenylene oxide) grafted with DABCO and Mg/Al lamellar double hydroxide

\author{
Dr. L. Pasquini ${ }^{1}$, R.-A. Becerra-Arciniegas ${ }^{1,2}$, Dr. R. Narducci ${ }^{2}$, Dr. E. Sgreccia ${ }^{2}$, V. \\ Gressel $^{2, a}$, Prof. M. L. Di Vona ${ }^{2, *}$, Prof. P. Knauth ${ }^{1, *}$ \\ ${ }^{1}$ Aix Marseille Univ, CNRS, MADIREL (UMR 7246) and International Associated \\ Laboratory: Ionomer Materials for Energy, Campus St Jérôme, 13013 Marseille, France \\ ${ }^{2}$ University of Rome Tor Vergata, Dep. Industrial Engineering, and \\ International Associated Laboratory: Ionomer Materials for Energy, 00133 Roma, Italy
}

\begin{abstract}
We studied composite anion exchange membranes made from poly(2,6-dimethyl-1,4phenylene oxide) (PPO) with grafted 1,4-diazabicyclo[2.2.2] octane (DABCO) and Mg/Al lamellar double hydroxide particles as inorganic filler. The mechanical and conductivity properties were measured in fully humidified conditions. The activation energy for conductivity amounts to $(0.20 \pm 0.01) \mathrm{eV}$. The degradation of the anion exchange membrane in $2 \mathrm{M} \mathrm{NaOH}$ at $60{ }^{\circ} \mathrm{C}$ was investigated during $168 \mathrm{~h}$ following the ionic conductivity, water uptake and ion exchange capacity as function of the alkaline treatment time. The degradation is rapid within the first hours and then slows down. The degradation was also studied by thermogravimetric analysis and FTIR spectroscopy, showing the various decomposition phenomena of the composite.

* Corresponding authors:

Philippe.Knauth@univ-amu.fr

divona@uniroma2.it
\end{abstract}

${ }^{\mathrm{a}}$ Internship of IUT Montpellier-Sète 


\section{Introduction}

The mediocre alkaline stability is the main obstacle contrasting the widespread application of anion exchange membranes in alkaline fuel cells and other electrochemical devices [1-8]. However, the availability of such membranes would allow avoiding the extensive use of platinum or related expensive noble-metal electrocatalysts for the oxygen reduction reaction [9-11]. The alkaline degradation can occur on functional groups, especially quaternary ammonium moieties [12-15], but also on the polymer backbone [3, 16], especially if it contains electron-withdrawing groups, such as sulfone. Polysulfones (PSU) $[17,18]$ are therefore considered less alkaline stable polymers and ionomers based on poly(2,6-dimethyl1,4-phenylene oxide) (PPO), which do not contain sulfone links, are expected to present a higher alkaline stability [15, 19-24], although the ether groups are still possible weak points [25-27].

We have previously reported the beneficial effect of bulky and stiff amines, such as 1,4diazabicyclo[2.2.2] octane (DABCO), which can mitigate the degradation effect by steric hindrance [5]. In the present work, we use quaternary ammonium groups made with DABCO grafted on PPO chains. The ionomer itself should therefore present a decent alkaline stability. Furthermore, we want to explore the synergistic effect of the formation of composites, especially using an inorganic solid that contains itself mobile anions, which can partly compensate the loss of ionic conductivity due to the presence of an inorganic filler [28, 29]. As recently reported, inorganic layered compounds in mixed matrix membranes improve the performance of AEM [30, 31]. Lamellar double hydroxides (LDH) [32] are layered ionic conducting inorganic solids that contain mobile anions in the interlamellar space, which can be exchanged and can help to maintain a certain level of conductivity even in low humidity environment [33]. LDH show exceptionally high and anisotropic 2D ion conduction [34, 35] via the presence in the layered structure of linked oxygenated groups allowing the establishment of a hydrogen bond network along the LDH surface. They might also mitigate the attack of anion exchange membranes in alkaline conditions by composite effects and reduce the membrane swelling and excessive water uptake. LDH can be prepared with various doping cations. We have previously reported the growth of $\mathrm{Zn}-\mathrm{Al} \mathrm{LDHs}$ in thin film form [36]. We have also studied Mg-Al [37] and Zn/Al [38] LDH as second phase in composites of PSU with grafted quaternary ammonium groups.

Consequently, we study in this work the properties and the alkaline stability of composite PPO-based ionomers containing quaternary ammonium groups with $\mathrm{DABCO}$ and $\mathrm{Mg}-\mathrm{Al}$ 
$\mathrm{LDH}$ as inorganic phase. The LDH composition was $\mathrm{Mg}_{0.66} \mathrm{Al}_{0.33}(\mathrm{OH})_{2}\left(\mathrm{NO}_{3}\right)_{0.33}$. The mobile nitrate ions can be exchanged against chloride or hydroxide ions.

The concentration of the inorganic compound is quite high (30 wt $\%$ ) to explore the beneficial effects on the membrane water uptake and degradation. The purpose of a very high loading is threefold: i) get as close as possible to a mainly inorganic membrane sustaining good mechanical properties, ii) minimize the degradation due to the loss of ionomeric groups, and iii) preserve the ionic conductivity of the composite membrane by creation of a percolating anion conducting inorganic part.

\section{Experimental}

\subsection{Products}

Poly(2,6-dimethyl-1,4-phenylene oxide) (PPO, MW = $50000 \mathrm{~g} / \mathrm{mol}$ ) and all reagents, such as 1,4-diazabicyclo[2.2.2] octane (DABCO), paraformaldehyde, trimethylchlorosilane, $\mathrm{SnCl}_{4}$, $\mathrm{Mg}\left(\mathrm{NO}_{3}\right)_{2} \cdot 6 \mathrm{H}_{2} \mathrm{O}$ and $\mathrm{Al}\left(\mathrm{NO}_{3}\right)_{3} \cdot 9 \mathrm{H}_{2} \mathrm{O}$, were reagent-grade and purchased from Sigma-Aldrich.

\subsection{Ionomer synthesis}

The ionomer was prepared as reported previously [24]. In short, PPO was first chloromethylated and subsequently quaternized by nucleophilic substitution with DABCO [38]. PPO (5.04 g, $42 \mathrm{mmol}$ ) was dissolved in $500 \mathrm{~mL}$ chloroform and $198 \mathrm{mmol}$ (5.98 g) of paraformaldehyde was introduced and stirred during $1 \mathrm{~h}$. Then $4.2 \mathrm{mmol}(0.46 \mathrm{~mL})$ of $\mathrm{SnCl}_{4}$ was added at room temperature. A solution of trimethylchlorosilane $(198 \mathrm{mmol}, 25 \mathrm{~mL})$ in chloroform was introduced dropwise during $2 \mathrm{~h}$ at RT. To obtain a degree of chloromethylation $\mathrm{DCl}=0.28$, the reaction temperature was kept at $45^{\circ} \mathrm{C}$ for $17 \mathrm{~h}$. After this time, the temperature was decreased and $150 \mathrm{~mL}$ of methanol added at RT until complete precipitation. The formed Cl-PPO was washed with methanol and dried in an oven at $60{ }^{\circ} \mathrm{C}$ for $48 \mathrm{~h}$.

The chloromethylated precursor was then quaternized in 1-methyl-2-pyrrolidinone (NMP) by reaction with an excess of $\mathrm{DABCO}$ to avoid the possible cross-linking reaction due to the presence of two nitrogens in the structure [1]. Typical quantities of reactants were $12.7 \mathrm{mmol}$ $(1.68 \mathrm{~g})$ of $\mathrm{Cl}-\mathrm{PPO}(\mathrm{DCl}=0.28)$ and $4.9 \mathrm{mmol}$ of DABCO $(0.56 \mathrm{~g})$ in $125 \mathrm{~mL} \mathrm{NMP}$, corresponding to a molar excess of 1.4 with respect to the functional ammonium groups; this means an excess of $10 \mathrm{~mol} \%$ with respect to the polymer. The reaction was carried out during $72 \mathrm{~h}$ at $70{ }^{\circ} \mathrm{C}$ under nitrogen flux. After this time, the excess of DABCO was eliminated by 
heating the solution for $2 \mathrm{~h}$ at $80{ }^{\circ} \mathrm{C}$ under vacuum using a liquid nitrogen trap and a rotary pump ( $210^{-6}$ bar). The remaining solution (about one third of the initial volume) was directly used for the casting procedure. The prepared membranes were repeatedly washed in deionized water to remove any remaining traces of $\mathrm{DABCO}$, which is water-soluble. The membranes were obtained in $\mathrm{Cl}$ form. The degree of functionalization ( $\mathrm{DF}=0.27)$, measured by Mohr titration (see below), was nearly identical to the initial DCl.

The structure of PPO-DABCO polymer in $\mathrm{Cl}$ form is shown in Figure 1.

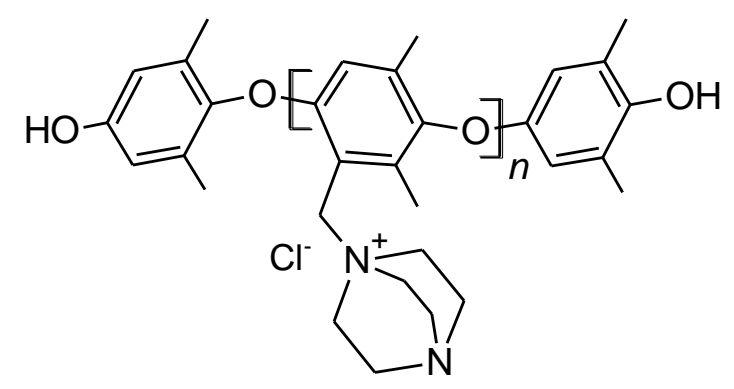

Figure 1. PPO-DABCO structure.

\subsection{LDH synthesis}

$\mathrm{Mg} / \mathrm{Al}-\mathrm{LDH}$ in nitrate form was synthesized by a co-precipitation method with a molar ratio $\mathrm{Mg} / \mathrm{Al}=2$ corresponding to a formula $\mathrm{Mg}_{0.66} \mathrm{Al}_{0.33}(\mathrm{OH})_{2}\left(\mathrm{NO}_{3}\right)_{0.33}$. De-carbonated water was used to prepare the two salt solutions and avoid the formation of $\mathrm{Mg} / \mathrm{Al}$ carbonates. $0.02 \mathrm{~mol}$ $\mathrm{Mg}\left(\mathrm{NO}_{3}\right)_{2} \cdot 6 \mathrm{H}_{2} \mathrm{O}$ and $0.01 \mathrm{~mol} \mathrm{Al}\left(\mathrm{NO}_{3}\right)_{3} \cdot 9 \mathrm{H}_{2} \mathrm{O}$ were slowly added in a flask at room temperature under magnetic stirring under a constant flow of $\mathrm{N}_{2}$ gas. A solution of $1 \mathrm{M} \mathrm{NaOH}$ was then added dropwise under magnetic stirring until $\mathrm{pH}=10.0$ was attained. The $\mathrm{pH}$ was controlled by in situ potentiometric titration. The resulting slurry was heated for $18 \mathrm{~h}$ at $80{ }^{\circ} \mathrm{C}$. The white precipitate was washed with deionized water many times and dried in an oven at 80 ${ }^{\circ} \mathrm{C}$ for $48 \mathrm{~h}$.

\subsection{Preparation of composite membranes}

PPO-DABCO composite membranes with $30 \mathrm{wt} \% \mathrm{LDH}$ were prepared by adding the filler to $20 \mathrm{~mL}$ of a $0.05 \mathrm{M}$ solution of PPO-DABCO in NMP. The resulting mixture was stirred for 4 $\mathrm{h}$ and evaporated to around $10 \mathrm{~mL}$ on a heating plate at $100{ }^{\circ} \mathrm{C}$. The viscous solution was then cast onto a Petri dish and dried in an oven at $100{ }^{\circ} \mathrm{C}$ during $48 \mathrm{~h}$. The composite membranes contain initially $\mathrm{Cl}^{-}$ions from the synthesis of PPO-DABCO, and $\mathrm{NO}_{3}{ }^{-}$ions from the 
synthesis of LDH. For this reason, the counterions were systematically exchanged with $\mathrm{Cl}^{-}$or $\mathrm{OH}^{-}$ions before any measurements (see below).

\subsection{Ion Exchange Capacity (IEC) by Mohr titration}

This method is based on ion exchange reactions and determines the chloride ion concentration by titration with silver nitrate. The anions, initially present in PPO-LDH samples, were exchanged by $\mathrm{Cl}^{-}$in a $1 \mathrm{M} \mathrm{NaCl}$ solution during $48 \mathrm{~h}$ at room temperature. Then, membranes were washed in deionized water for 30 minutes and transferred into $20 \mathrm{~mL}$ of $1 \mathrm{M} \mathrm{Na}_{2} \mathrm{SO}_{4}$ solution to exchange $\mathrm{Cl}^{-}$by $\mathrm{SO}_{4}{ }^{2-} ; 1 \mathrm{~mL}$ of $0.25 \mathrm{M} \mathrm{K}_{2} \mathrm{CrO}_{4}$ indicator solution was added. As the $\mathrm{AgNO}_{3}$ solution was slowly introduced, a precipitate of $\mathrm{AgCl}$ formed (equation 1). The end-point of the titration was reached when all the chloride ions were precipitated. Then additional silver ions reacted with the indicator, potassium chromate, to form a red-brown precipitate (equation 2).

$$
\begin{aligned}
& \mathrm{Ag}^{+}(a q)+\mathrm{Cl}^{-}(a q) \rightarrow \mathrm{AgCl}(s) \\
& 2 \mathrm{Ag}^{+}(a q)+\mathrm{CrO}_{4}^{2-}(a q) \rightarrow \mathrm{Ag}_{2} \mathrm{CrO}_{4}(s)
\end{aligned}
$$

In this work, a $0.01 \mathrm{M} \mathrm{AgNO}_{3}$ solution was prepared for the Mohr titration avoiding sunlight. The IEC is expressed as the quantity of anions that can be exchanged by a specific mass of dry ionomer:

$$
I E C=\frac{\text { concentration } \mathrm{AgNO}_{3} \text { solution } * \text { volume }}{\text { dry weight }} \mathrm{meq} / \mathrm{g}
$$

\subsection{Water uptake}

The water uptake WU was measured for both $\mathrm{Cl}$ and $\mathrm{OH}$ forms. The membranes in $\mathrm{Cl}$ form were obtained by immersion in $1 \mathrm{M} \mathrm{NaCl}$ solution during $48 \mathrm{~h}$ then carefully washed in deionized water. The $\mathrm{OH}$ form was obtained by immersion of the membranes in $2 \mathrm{M} \mathrm{KOH}$ during $48 \mathrm{~h}$ to exchange $\mathrm{Cl}^{-}$ions and washing them 3 times in deionized water. Manipulations were done ensuring that the membranes were as little as possible in contact with air avoiding carbonatation problems.

The water uptake is defined by the mass of wet sample $\left(m_{w e t}\right)$ and the mass of dry sample $\left(m_{d r y}\right)$ :

$$
W U(\%)=\frac{m_{w e t}-m_{d r y}}{m_{d r y}} * 100
$$

To determine the wet mass, samples were removed from the deionized water and carefully wiped with adsorbing paper. To determine the dry mass, the samples were stored in a desiccator over $\mathrm{P}_{2} \mathrm{O}_{5}$ during $48 \mathrm{~h}$ to remove completely the water. 
The Water Uptake WU (in \%) and IEC (in meq/g) permit to calculate the hydration number $\lambda$, which represents the number of water molecules per quaternary ammonium group:

$$
\lambda=\frac{1000 *(W U / 100)}{I E C * 18}
$$

\subsection{Mechanical measurements}

Tensile stress-strain tests were performed using an Adamel-Lhomargy DY30 uniaxial traction machine at $25{ }^{\circ} \mathrm{C}$ on fully humidified membranes in $\mathrm{Cl}$ form with a traction rate of $5 \mathrm{~mm} / \mathrm{min}$. After immersion of the membranes in deionized water for $24 \mathrm{~h}$, in order to reach the maximum humidification, samples of $5 \mathrm{~mm}$ width and $25 \mathrm{~mm}$ length were first carefully cut in the centre of the membranes to remove inhomogeneous parts at the borders and then rapidly installed between the clamps of the machine. The short duration of the test allows maintaining full humidification during the experiment.

\subsection{Thermogravimetry}

The thermogravimetric experiments were performed using a TA Instruments TGA Q500 high resolution analyser. Around $7 \mathrm{mg}$ of $\mathrm{Cl}$ form ionomers were placed in Pt sample holders and heated with a maximum rate of $3 \mathrm{~K} / \mathrm{min}$ from 30 to $600{ }^{\circ} \mathrm{C}$ in air. Comparative thermograms were recorded after degradation of the ionomers in $2 \mathrm{M} \mathrm{NaOH}$ at $60{ }^{\circ} \mathrm{C}$ for $168 \mathrm{~h}$.

\subsection{FTIR spectroscopy}

FTIR spectra were recorded between 4000 and $450 \mathrm{~cm}^{-1}$ using a Perkin Elmer Spectrum 2 IR spectrometer equipped with an ATR crystal diamond module. The membrane was directly analysed by squeezing it on the diamond window at room temperature and humidity in $\mathrm{Cl}$ form.

\subsection{Ionic conductivity by impedance spectroscopy}

The sample resistance impedance of $\mathrm{Cl}$ form membranes was measured at full humidification. The samples in $\mathrm{Cl}$ form were first immersed in deionized water during $24 \mathrm{~h}$; after removing excess water on the surface with absorbing paper, they were immediately introduced inside a hermetically closed Swagelok cell with stainless steel electrodes. The analysis was performed between $1 \mathrm{~Hz}$ and $6 \mathrm{MHz}$ with a signal amplitude of $20 \mathrm{mV}$ using a VSP-300 Electrochemical Impedance Spectrometer (Biologic science instruments). The resistance of the membranes in 
fully humidified form was obtained at 25, 40, 60 and $80{ }^{\circ} \mathrm{C}$ from a Nyquist plot by non-linear least-square fitting. The equivalent circuit was a classical series arrangement of two resistance-constant phase elements in parallel. The ionic conductivity $\sigma$ was calculated using equation (6) with the resistance $\mathrm{R}$, the membrane thickness d, typically 60-80 $\mu \mathrm{m}$, and the electrode area $\mathrm{A}=0.264 \mathrm{~cm}^{2}$.

$$
\sigma=\mathrm{d} /(\mathrm{A} * \mathrm{R})
$$

\subsection{Alkaline stability tests}

To carry out the stability tests, 8 samples of each membrane were cut in rectangles of approximately $40 \mathrm{mg}$ mass. First, the membranes were washed by immersing them in deionized water for $48 \mathrm{~h}$ in an oven at $60{ }^{\circ} \mathrm{C}$. The stability tests were performed by putting the samples into $2 \mathrm{M} \mathrm{KOH}$ at $60^{\circ} \mathrm{C}$ for various times between 2 and $168 \mathrm{~h}$ inside a Teflon container fluxed with nitrogen. The samples were then transformed into the $\mathrm{Cl}$ form by immersion in $2 \mathrm{M} \mathrm{NaCl}$ solution during $48 \mathrm{~h}$ and then washed with deionized water. The sample conductivity, IEC and WU were then determined as described above.

\section{Results and discussion}

\subsection{Mechanical properties}

Figure 2 shows a typical mechanical stress-strain test.

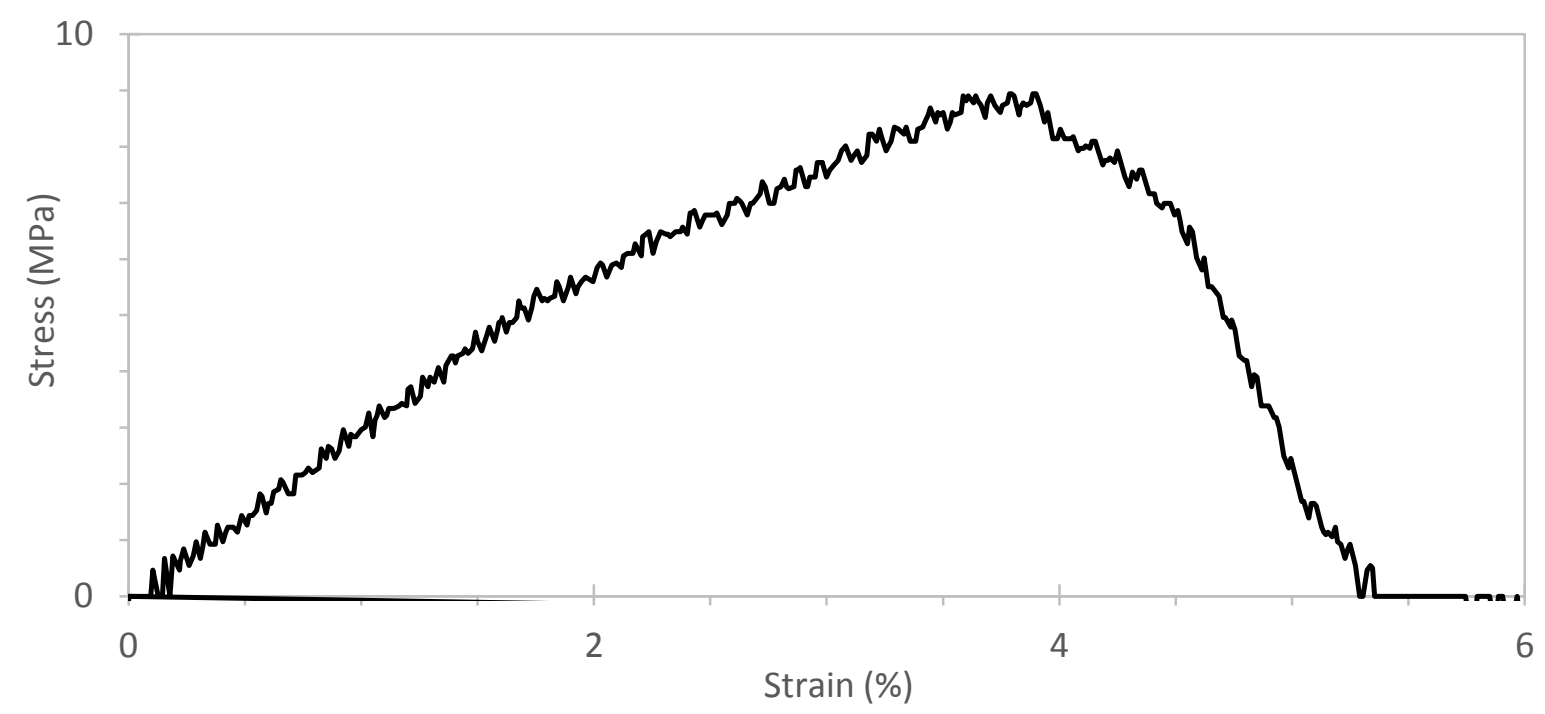

Figure 2. Tensile stress-strain test for PPO-DABCO in $\mathrm{Cl}$ form at full humidification at $25^{\circ} \mathrm{C}$. 
The mechanical properties were determined in fully humidified environment to simulate the operative condition of membranes. The Young modulus $(\mathrm{E}=280 \pm 20 \mathrm{MPa})$ and tensile strength (TS $=9 \pm 2 \mathrm{MPa}$ ) are consistent with a highly hydrated membrane, because the high dielectric constant of water reduces the Van der Waals interactions between ionomer chains $[39,40]$. The formation of composites leads to a slight increase of the Young modulus $(\mathrm{E}=$ $320 \pm 60 \mathrm{MPa}$ ); the tensile strength decreases instead (TS $=3 \pm 2 \mathrm{MPa})$. The elongation at break is quite low $(<5 \%)$ in all cases.

\subsection{Temperature dependence of the ionic conductivity}

The chloride ion conductivities of PPO-DABCO and PPO-DABCO + LDH between 25 and $80{ }^{\circ} \mathrm{C}$ are reported in Table 1 and plotted vs the reciprocal absolute temperature in Figure 3.

Table 1. Chloride ion conductivity of PPO-DABCO and PPO-DABCO + LDH membranes.

\begin{tabular}{|c|c|c|}
\hline Temperature $\left({ }^{\circ} \mathrm{C}\right)$ & $\begin{array}{c}\sigma(\mathrm{PPO}-\mathrm{DABCO}) \\
(\mathrm{S} / \mathrm{cm})\end{array}$ & $\begin{array}{c}\sigma(\mathrm{PPO}-\mathrm{DABCO}+\mathrm{LDH}) \\
(\mathrm{S} / \mathrm{cm})\end{array}$ \\
\hline 25 & 2.0 & 1.3 \\
\hline 40 & 3.0 & 1.8 \\
\hline 60 & 4.3 & 2.6 \\
\hline 80 & 7.0 & 4.4 \\
\hline
\end{tabular}

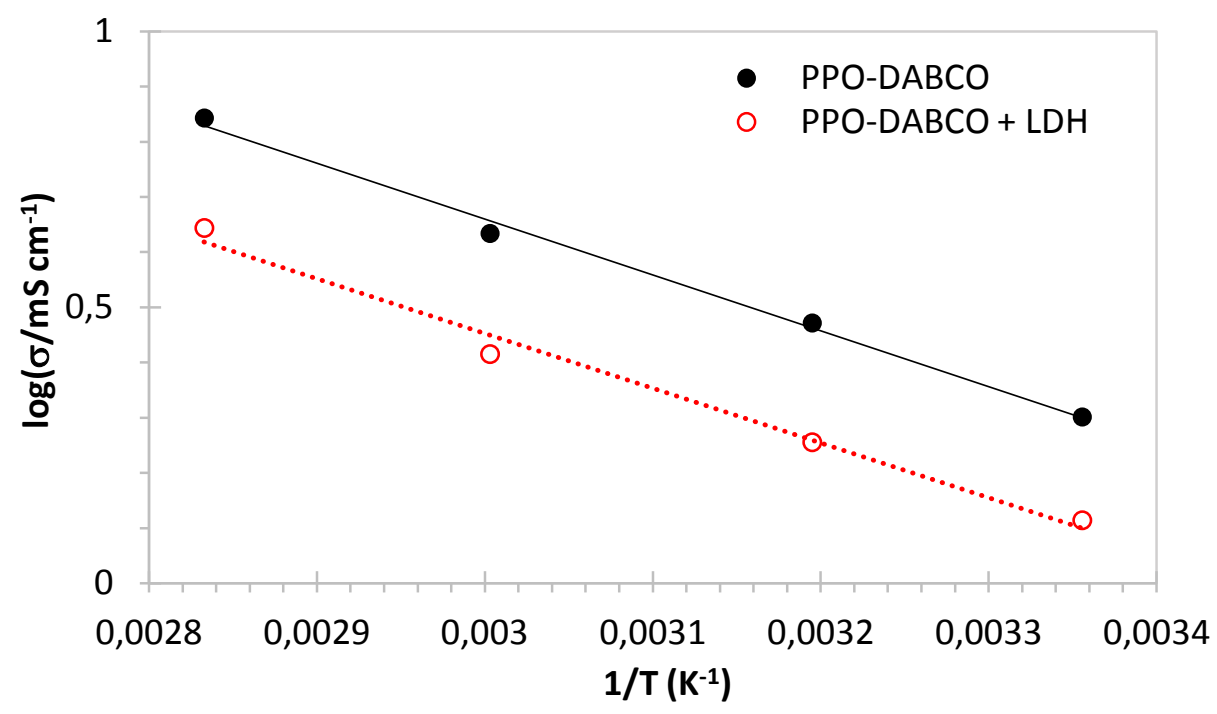

Figure 3. Chloride ion conductivity dependence on temperature at full humidification. 
The presence of the inorganic phase reduces the ionic conductivity, as previously observed in other composites [37], but the decrease is relatively limited also considering the high quantity of the filler in the membranes. The low decrease observed is attributable to the presence in the LDH structure of mobile anions that contribute to the conductivity of samples, although they are not enough to compensate the loss of conductivity. One must also take into account the necessary interconnection between two-dimensional ion-conduction planes in LDH and onedimensional ion-conduction channels in the ionomer limiting the percolative anion transport through the membranes. Below the glass transition temperature of the ionomer (which is nearly $200{ }^{\circ} \mathrm{C}$ for related PSU-DABCO [39]), the activation energy $E a$ for chloride ion conduction can be calculated using an Arrhenius-type equation:

$$
\sigma=\sigma_{0} e^{-\frac{E a}{R T}}
$$

$\sigma_{0}$ is the prefactor, $R$ is Boltzmann's constant and $T$ is the absolute temperature. The activation energy, calculated from the graph in Figure 3, is very similar for both materials and amounts to $(0.20 \pm 0.01) \mathrm{eV}$ in good agreement with other ionomers in $\mathrm{Cl}$ form [41].

\subsection{Degradation test: ionic conductivity}

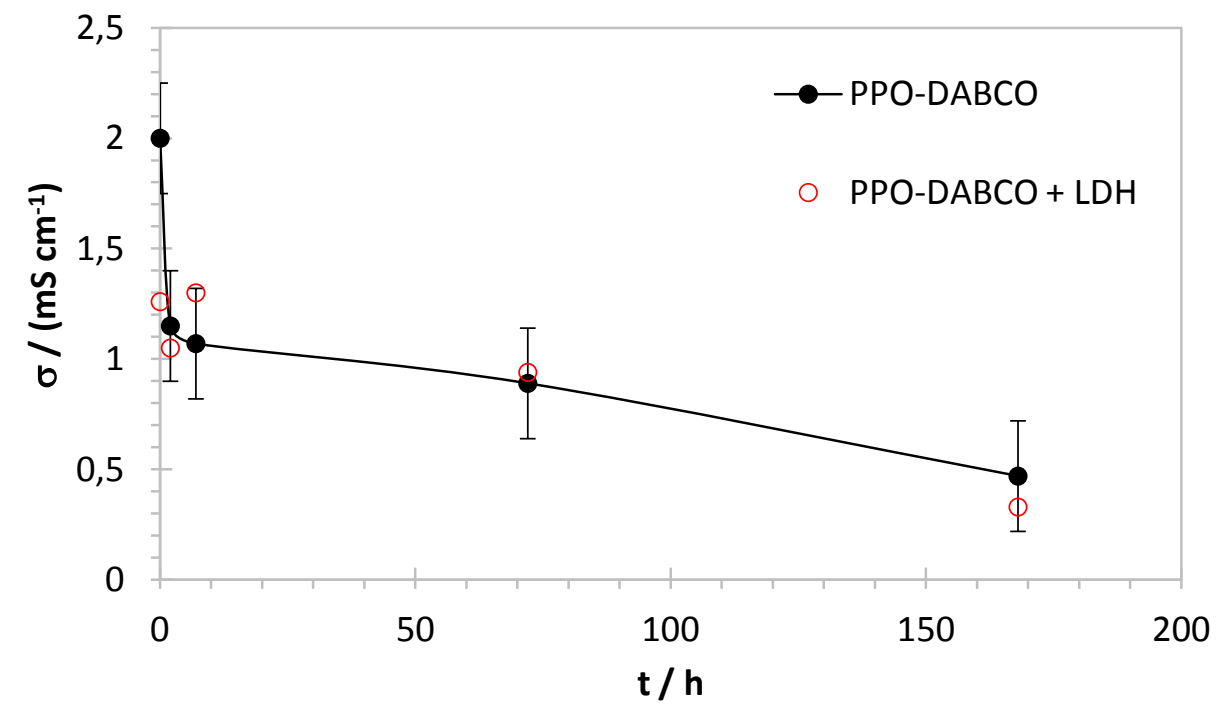

Figure 4. Chloride ion conductivity (including error bars) as function of the alkaline treatment time.

Figure 4 shows the ionic conductivity of pristine and composite membranes after the aging in $\mathrm{KOH}$ at different times. The ionic conductivity decrease of PPO-DABCO is similar to previously reported data for short side-chain ionomers (23\% of residual conductivity after 168 
$\mathrm{h}$ of alkaline treatment) [21]. The composite membrane shows a comparable or slightly better degradation resistance. One should mention that the alkaline degradation is strongly correlated with the hydration. For low hydration numbers, typically below 4, the incomplete solvation shell of the hydroxide ions increases their reactivity and amplifies the alkaline degradation $[42,43]$.

\subsection{Degradation test: ion exchange capacity}

A similar behaviour can be noticed observing the ion exchange capacity dependence on the time of aging obtained from Mohr titration (Figure 5). The IEC decrease is correlated with the loss of ammonium groups in alkaline conditions. The strongest degradation is observed within the first $12 \mathrm{~h}$ of the treatment. At longer times, the degradation is much slower. We have previously attributed this result to a pseudo second-order kinetics of the degradation reaction [24].

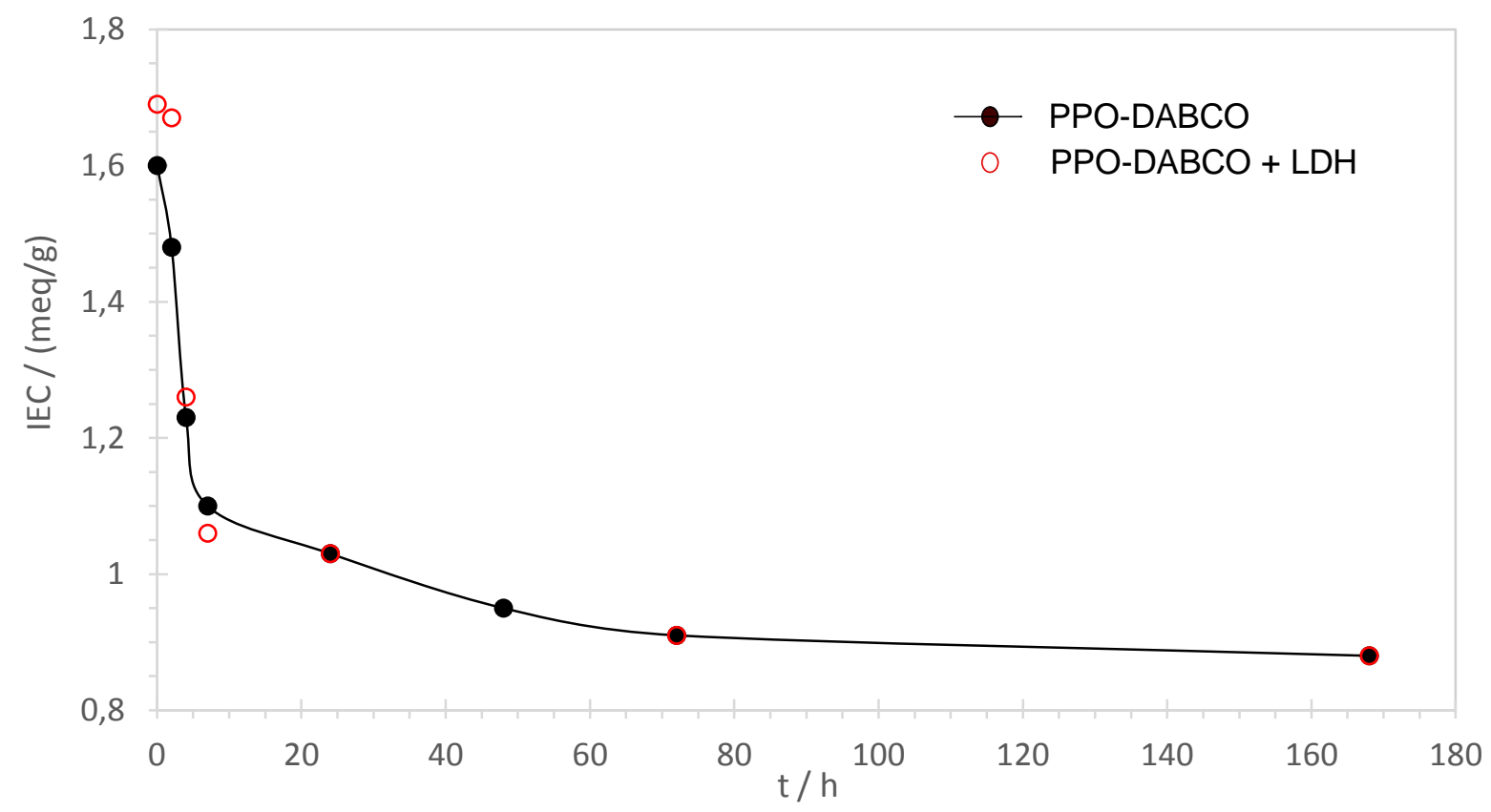

Figure 5. Ion exchange capacity as function of the alkaline treatment time.

\subsection{Degradation test: water uptake}

Water uptake data for $\mathrm{OH}$ and $\mathrm{Cl}$ forms are shown in Figure 6. One can notice the about twice higher water uptake for the $\mathrm{OH}$ form in agreement with the expectation, given that hydroxide 
anions are much more hydrated than chloride anions [44]. The decrease with alkaline treatment time is relatively low.

In the composite, the water uptake is slightly lower for both $\mathrm{OH}$ and $\mathrm{Cl}$ forms, although the difference is not large. Especially in the $\mathrm{OH}$ form, WU increases with the time of the aging, apparently in contradiction with the decrease of the IEC. A possible explanation is that the aging in alkaline condition of the composite membranes for a long time acts on LDH as a post synthetic hydrothermal treatment. It is reported in the literature that the hydrothermal aging may lead to particles with larger size altering the absorption of water [45, 46]. This effect might justify the observed larger scatter for the composite.
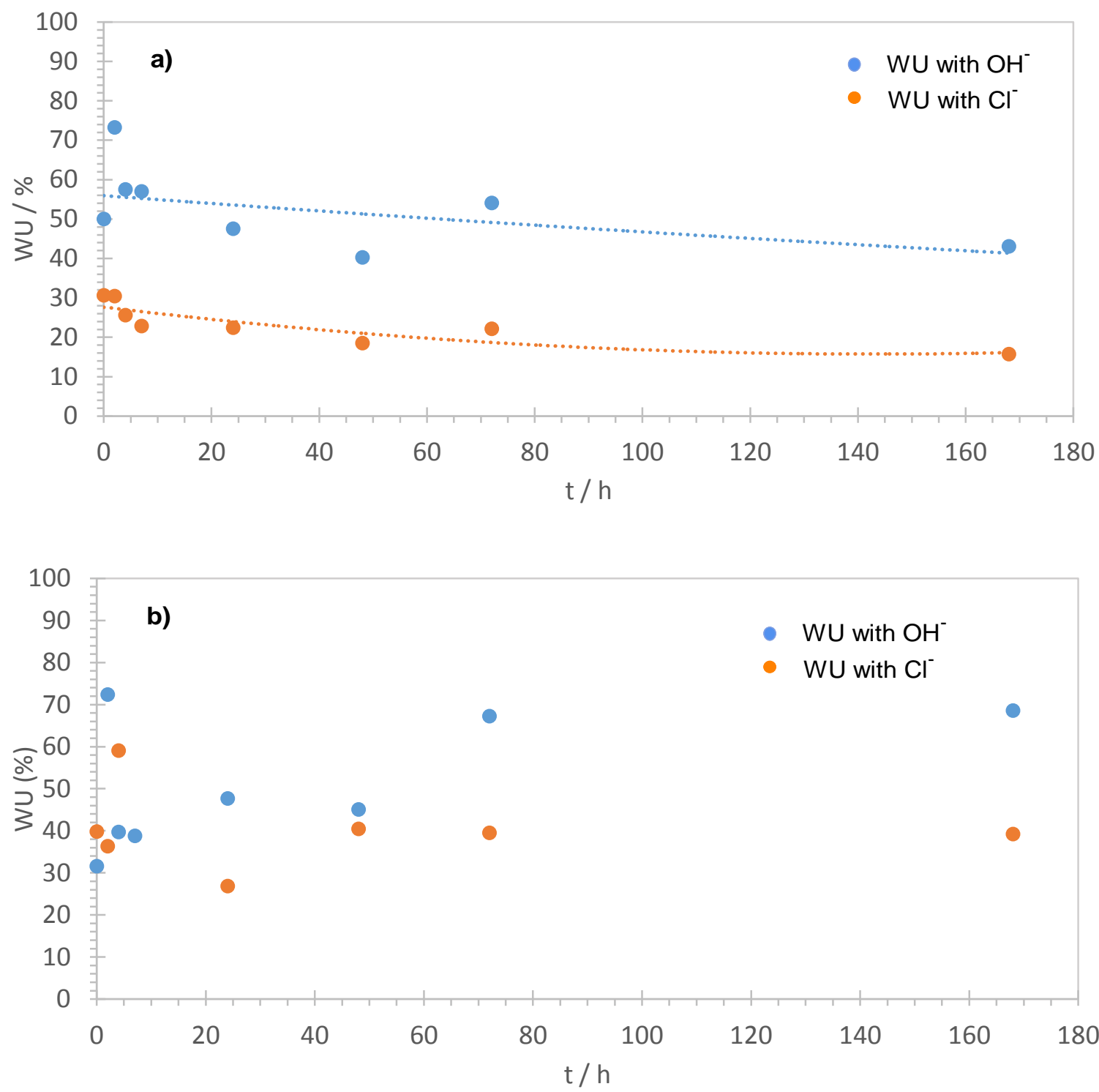

Figure 6. Water uptake as function of the alkaline treatment time. a) PPO-DABCO $(\mathrm{OH}$ and $\mathrm{Cl}$ form). b) PPO-DABCO + $\mathrm{LDH}$ ( $\mathrm{OH}$ vs $\mathrm{Cl}$ form). 
The evolution of the hydration number $\lambda$ for the composite membrane is reported in Figure 7 and indicates that the change in the LDH morphology starts after $60 \mathrm{~h}$ in $\mathrm{KOH}$.

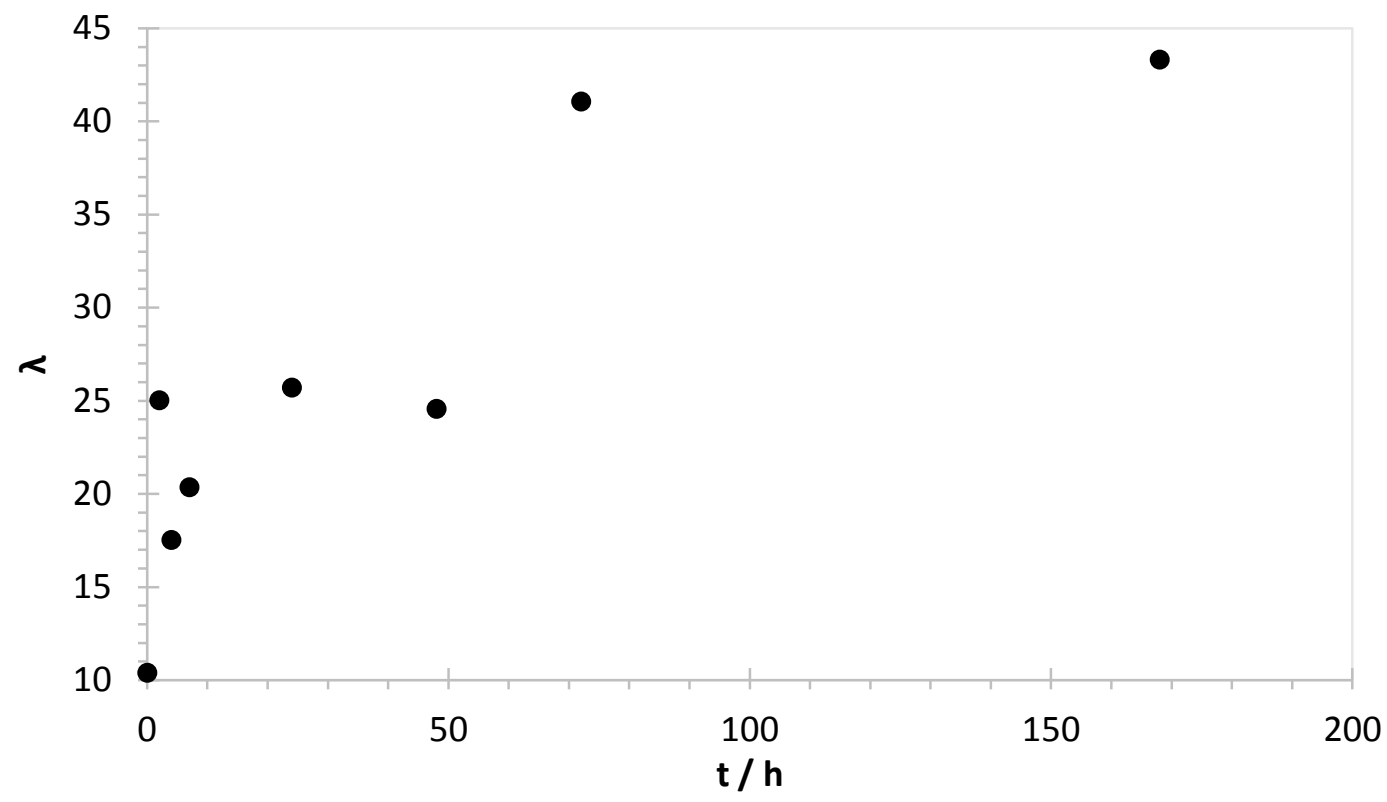

Figure 7. Hydration number of composite PPO-DABCO + LDH as function of the alkaline treatment time.

3.6. Thermogravimetric analysis

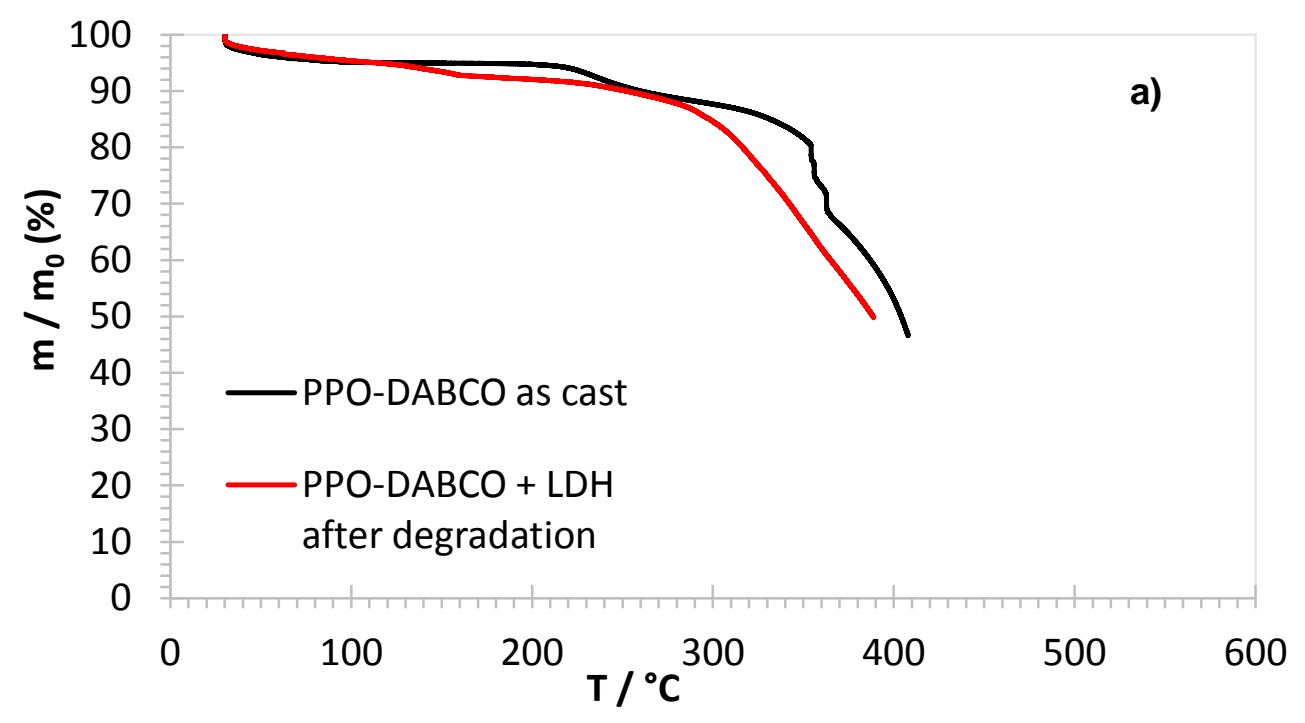



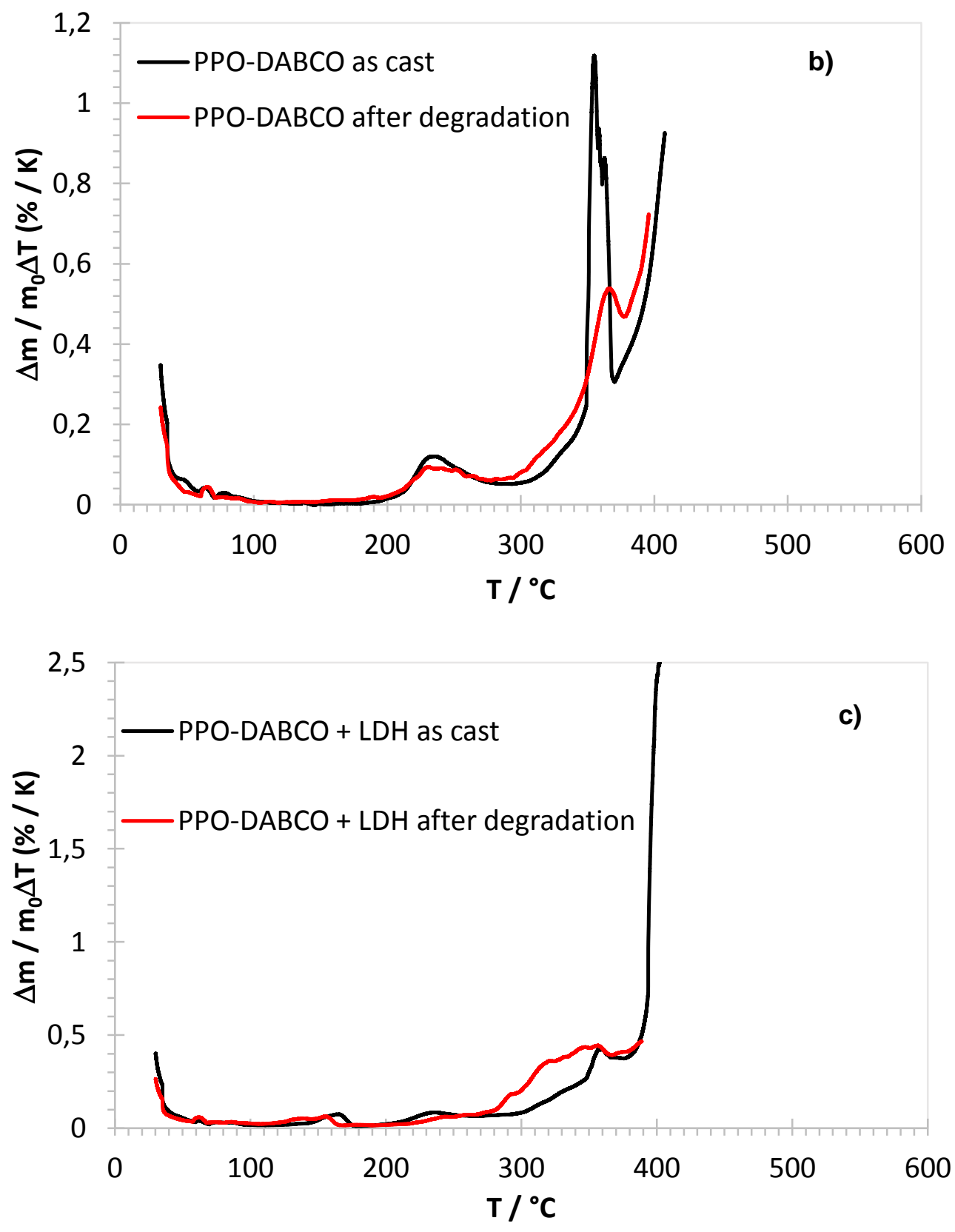

Figure 8. Thermogravimetric analysis in air. a) Mass loss curves for pristine PPO-DABCO and PPO-DABCO+LDH after alkaline degradation. b) Differential thermogravimetric curves for PPO-DABCO before and after alkaline degradation. c) Differential thermogravimetric curves for PPO-DABCO before and after alkaline degradation.

Figure 8a shows a comparison of typical thermogravimetric curves for pristine PPO-DABCO and PPO-DABCO+LDH after alkaline degradation. For PPO-DABCO, the thermogram shows several, well-separated mass losses: after the initial loss of water (5\%), a broad mass loss above $200{ }^{\circ} \mathrm{C}$ may be attributed to the removal of $\mathrm{DABCO}$, which was previously 
observed at a similar temperature [21]. The corresponding mass loss of about $15 \%$ is slightly below the calculated value. A second sharp mass loss of $18 \%$ around $360{ }^{\circ} \mathrm{C}$ is attributed to the loss of the two methyl groups of PPO, which decompose prior to the main chain [47]; the calculated mass loss is in excellent agreement with the experiment. The remaining mass above $380{ }^{\circ} \mathrm{C}(62 \%)$ is in very good agreement with the calculated value for the remaining polymer backbone. For degraded PPO-DABCO+LDH, the mass loss above $130{ }^{\circ} \mathrm{C}$ corresponds to the elimination of interlayer structural water [48, 49]; the following decomposition above $200{ }^{\circ} \mathrm{C}$ is very diffuse with a continuously sloping curve. It is impossible to distinguish the various effects and the differential thermogravimetric curves (DTG) are more useful in this respect (see below). The residual mass of around $16 \%$ at the end of the experiment belongs to oxides due to decomposition of the $\mathrm{LDH}$; the difference with the initial percentage of $\operatorname{LDH}(30 \%)$ is due to the loss of anions, as previously described [48, 50].

To improve the analysis, the differential thermogravimetric curves (DTG) are more useful: each peak corresponds to a thermal degradation process. For PPO-DABCO (Figure 8b) after the initial mass loss due to membrane dehydration up to $100{ }^{\circ} \mathrm{C}$, the first peak with a maximum at $230^{\circ} \mathrm{C}$ is related to the loss of $\mathrm{DABCO}$. One can notice that the peak is lower after the alkaline treatment, where a part of the quaternary ammonium moieties is lost. The second peak with a maximum near $360^{\circ} \mathrm{C}$, attributed to the methyl groups of the PPO backbone [24], is very significantly reduced after the alkaline treatment. Ehlers reported that the decomposition mechanism of PPO begins with the cleavage of the ether linkages and simultaneous removal of the methyl groups [47]; probably a similar mechanism is acting during the alkaline degradation. The final large peak with a maximum near $415{ }^{\circ} \mathrm{C}$ corresponds to the decomposition of the remaining polymer backbone.

In PPO-DABCO+LDH composites (Figure 8c), the first peak with a maximum near $150{ }^{\circ} \mathrm{C}$ belongs to removal of interlayer water of $\mathrm{LDH}[48,50]$. In the broad signal starting around $200{ }^{\circ} \mathrm{C}$, one can first observed the loss of DABCO with an intermediate maximum at $230{ }^{\circ} \mathrm{C}$. At higher temperature, the decomposition reactions of LDH overlap the decomposition of the polymer. They include the loss of intercalated structural water, dehydroxylation of the brucite-like layer and removal of interlayer chloride ions, giving a mixture of oxides [50]. These processes in the LDH structure were reported at comparable temperatures in the literature, e. g. above $280{ }^{\circ} \mathrm{C}$ and up to $500{ }^{\circ} \mathrm{C}$ with a total weight loss of $45 \%$ [50] and with a maximum at 310 [49] or $320{ }^{\circ} \mathrm{C}$ [48]. One can notice that the alkaline treatment strongly modified the aspect of the DTG curve. The smaller and broader peaks are related to more 
continuous decomposition processes (cf. Figure 8a). Evidently, LDH is modified during the alkaline treatment and some reactions may occur, possibly related to the amphoteric nature of aluminium oxide. The peak of the PPO main chain degradation has a maximum at $410{ }^{\circ} \mathrm{C}$, slightly below PPO-DABCO, probably due to the interaction with the inorganic component. After the alkaline treatment, a second peak with a maximum at $420{ }^{\circ} \mathrm{C}$ is observed, corresponding to further decomposition processes of $\mathrm{LDH}$, which continue up to $500{ }^{\circ} \mathrm{C}$ as previously demonstrated [50].

\subsection{FTIR spectroscopic analysis}

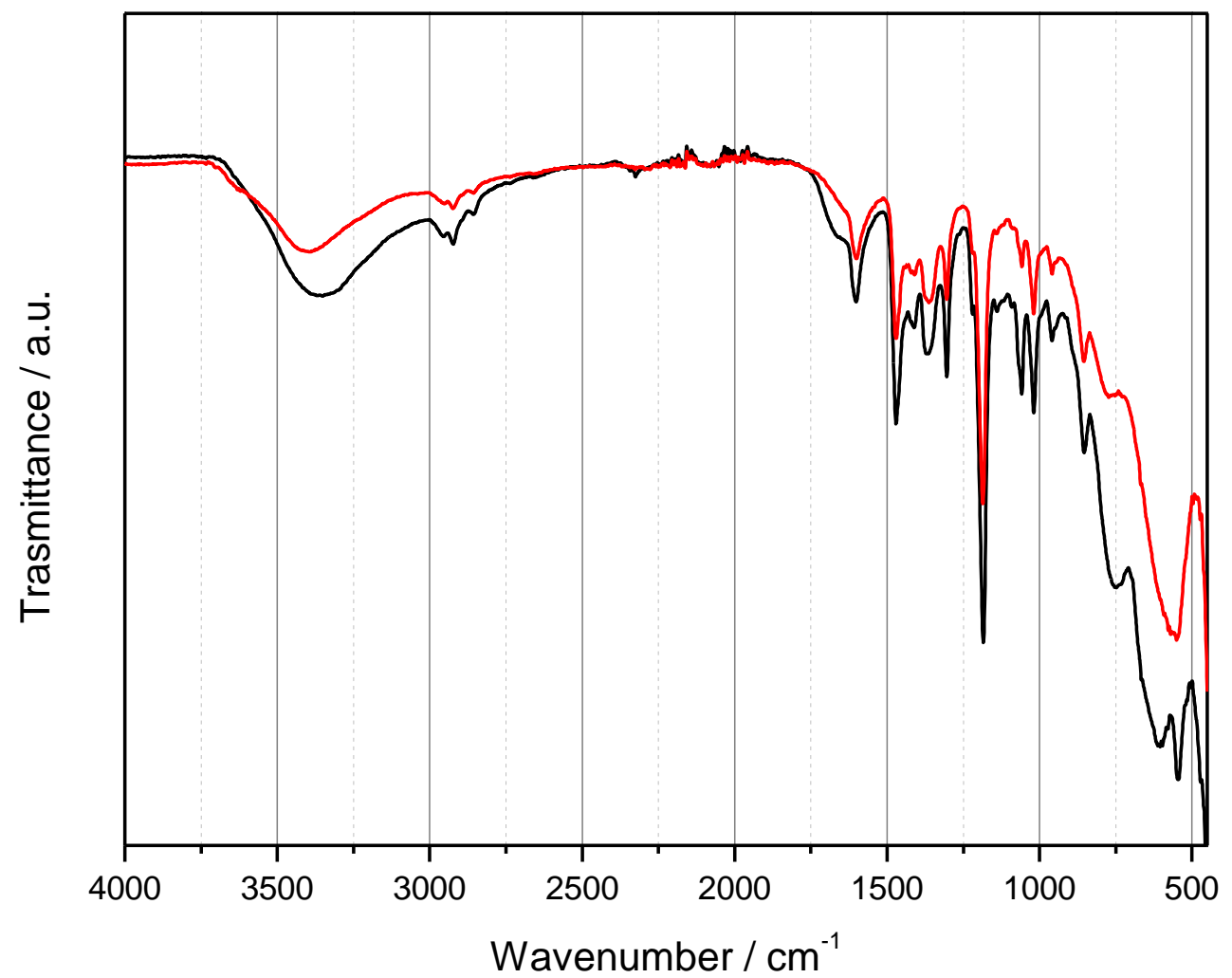

Figure 9. FTIR spectra of pristine PPO-DABCO+LDH (black line) and aged PPO-DABCO $+\mathrm{LDH}$ in $\mathrm{Cl}$ form (red line).

Figure 9 shows the FTIR analysis of PPO-DABCO+LDH in chloride form before and after the treatment in $2 \mathrm{M} \mathrm{KOH}$ at $60^{\circ} \mathrm{C}$ for $168 \mathrm{~h}$. Absorptions of the PPO backbone are present in both spectra: the stretching vibration of phenyl rings at 1600 and $1470 \mathrm{~cm}^{-1}$ and the 
symmetrical and asymmetrical stretching vibrations of the C- O- C linkages at 1185 and $1305 \mathrm{~cm}^{-1}$ [24].

The intensity of the $\mathrm{OH}$ stretching absorption around $3400 \mathrm{~cm}^{-1}$ is lower for the aged sample, which may be related to the loss of hydrophilic ammonium groups after the $\mathrm{KOH}$ treatment. This large band is due to vibrations of adsorbed water, vibration of $\mathrm{HO} \cdots \mathrm{OH}$ moieties, and vibrations of structural $\mathrm{OH}$ groups present in the $\mathrm{LDH}$ structure. The absorption maximum is at $3365 \mathrm{~cm}^{-1}$ and $3410 \mathrm{~cm}^{-1}$ for pristine and aged membranes respectively. The $\mathrm{OH}$ stretch is generally affected by the strength of the hydrogen bond that depends on the surrounding environment; the strongest hydrogen bonds absorb at the lowest vibrational frequency [51].

Typical C-N vibrations are observed for both samples at $1020 \mathrm{~cm}^{-1}$ [52] that overlap with the deformation mode of Al-OH [53]. Quaternary ammonium moieties absorb at 1060 and 1470 $\mathrm{cm}^{-1}$ [54]. The latter signal overlaps with PPO modes, resulting in a single broad band in the spectrum. The band at $1060 \mathrm{~cm}^{-1}$ shows a lower intensity in the aged membrane indicating some loss of ammonium moieties although the absorption at $1370 \mathrm{~cm}^{-1}$, due to out-of-plane bending of $\mathrm{CH}_{2}$ and typical of DABCO derivative, is unchanged [37]. The high intensity of this band in the aged composite is probably due to the overlap of the absorption of $\mathrm{CO}_{3}{ }^{2-}$ ions, reported around $1362 \mathrm{~cm}^{-1}$, present in the $\mathrm{LDH}$ interlayer after the long treatment in $\mathrm{KOH}$ [55]. The main differences between pristine and aged samples are in the fingerprint region especially in the range 500-650 $\mathrm{cm}^{-1}$ where the two typical signals of DABCO, centred at 550 and $610 \mathrm{~cm}^{-1}$ appear, indicating a modification in the aged membrane [56]. The band at 550 $\mathrm{cm}^{-1}$ also overlaps with hydroxyl absorption due to the Mg-Al LDH [53]. Very similar spectra are observed for PPO-DABCO samples before and after the aging.

\section{Conclusions}

The idea of this work was to explore the effect of inorganic phase particles in large amount dispersed in an ionomer matrix in order to improve the alkaline and hydrolytic stability of anion exchange membranes. The second phase was a $\mathrm{Mg} / \mathrm{Al}$ lamellar double hydroxide, which was itself anion conducting. AEM could be prepared successfully and their conductivity was relatively slightly reduced in comparison with the pristine ionomer. The degradation behaviour, studied by ex situ conductivity, water uptake and ion exchange capacity measurements, was also relatively similar to the pristine ionomer with a relatively fast degradation during the first hours. Thermogravimetric experiments and FTIR spectra 
made before and after the alkaline degradation gave complementary information on the degradation processes.

Evidently, the approach of a high anion-conducting filler content has not improved sufficiently the alkaline resistance of the membranes and the other key properties are also not significantly enhanced. Future work might instead be focused on a better dispersion of the inorganic compound into the ionomer, for example by in situ sol-gel synthesis or similar means, and by a more clever exploitation of the 2D morphology of LDH particles.

\section{Acknowledgment}

The authors want to thank Prof. F. Costantino (Univ. Perugia, Italy) for recording X-ray diffractograms of the $\mathrm{LDH}$ powders.

\section{Conflict of Interest}

The authors declare no conflict of interest.

Keywords: degradation; ion exchange capacity; ionic conductivity; membranes; nanoparticles

\section{References}

[1] B. Bauer, H. Strathmann, F. Effenberger Desalination. 1990, 79, 125-144.

[2] A. Jasti, S. Prakash, V. K. Shahi J. Membr. Sci. 2013, 428, 470-479.

[3] M. A. Hickner, A. M. Herring, E. B. Coughlin J. Polym Sci Pol Phys. 2013, 51, 1727-1735.

[4] Y. J. Wang, J. L. Qiao, R. Baker, J. J. Zhang Chem. Soc. Rev. 2013, 42, 5768-5787.

[5] M. L. Di Vona, R. Narducci, L. Pasquini, K. Pelzer, P. Knauth Int. J. Hydrog. Energy.. 2014, 39, 14039-14049.

[6] D. R. Dekel J. Power Sources. 2018, 375, 158-169.

[7] C. G. Arges, L. Zhang Acs Appl. Energy Mater. 2018, 1, 2991-3012.

[8] J. R. Varcoe, P. Atanassov, D. R. Dekel, A. M. Herring, M. A. Hickner, P. A. Kohl, A. R. Kucernak, W. E. Mustain, K. Nijmeijer, K. Scott, T. W. Xu, L. Zhuang Energy Environ Sci. 2014, 7, 3135-3191.

[9] J. R. Varcoe, R. C. T. Slade Fuel Cells. 2005, 5, 187-200.

[10] D. Grumelli, B. Wurster, S. Stepanow, K. Kern Nat. Commun. 2013, 4, 6.

[11] Z. F. Pan, L. An, T. S. Zhao, Z. K. Tang Prog Energ Combust. 2018, 66, 141-175.

[12] M. G. Marino, K. D. Kreuer ChemSusChem. 2015, 8, 513-523.

[13] Z. Sun, B. C. Lin, F. Yan ChemSusChem. 2018, 11, 58-70.

[14] J. J. Chen, C. P. Li, J. C. Wang, L. Li, Z. D. Wei J. Mater. Chem. A. 2017, 5, 6318-6327.

[15] J. Parrondo, M. S. J. Jung, Z. Y. Wang, C. G. Arges, V. Ramani J. Electrochem. Soc. 2015, 162, F1236-F1242.

[16] A. D. Mohanty, S. E. Tignor, J. A. Krause, Y. K. Choe, C. Bae Macromolecules. 2016, 49, 3361 3372. 
[17] S. Vico, B. Palys, C. Buess-Herman Langmuir. 2003, 19, 3282-3287.

[18] M. J. El-Hibri, S. A. Weinberg in Polysulfones, Vol., John Wiley \& Sons, Inc., 2002.

[19] J. Pan, J. J. Han, L. Zhu, M. A. Hickner Chem. Mater. 2017, 29, 5321-5330.

[20] L. Liu, X. M. Chu, J. Y. Liao, Y. D. Huang, Y. Li, Z. Y. Ge, M. A. Hickner, N. W. Li Energy Environ. Sci. 2018, 11, 435-446.

[21] R. A. Becerra-Arciniegas, R. Narducci, G. Ercolani, E. Sgreccia, L. Pasquin, M. L. Di Vona, P. Knauth J. Phys. Chem. C. 2020, 124, 1309-1316.

[22] C. G. Arges, L. H. Wang, J. Parrondo, V. Ramani J. Electrochem. Soc. 2013, 160, F1258-F1274.

[23] T. P. Pandey, H. N. Sarode, Y. T. Yang, Y. Yang, K. Vezzu, V. Di Noto, S. Seifert, D. M. Knauss, M. W. Liberatore, A. M. Herring J. Electrochem. Soc. 2016, 163, H513-H520.

[24] R. A. Becerra-Arciniegas, R. Narducci, G. Ercolani, S. Antonaroli, E. Sgreccia, L. Pasquini, P. Knauth, M. L. Di Vona Polymer. 2019, 185, 121931.

[25] A. Amel, N. Yitzhack, A. Beylin, J. Pan, M. A. Hickner, Y. Ein-Eli J. Electrochem. Soc. 2018, 165, F1133-F1138.

[26] J. Parrondo, Z. Y. Wang, M. S. J. Jung, V. Ramani PHYS CHEM. CHEM PHYS. 2016, 18, 19705-19712.

[27] A. D. Mohanty, S. E. Tignor, J. A. Krause, Y.-K. Choe, C. Bae Macromolecules. 2016, 49, 33613372.

[28] P. Knauth J. Electroceram. 2000, 5, 111-125.

[29] Z. Derbali, A. Fahs, J. F. Chailan, I. V. Ferrari, M. L. Di Vona, P. Knauth Int. J. Hydrog. Energy. 2017, 42, 19178-19189.

[30] Y. Furukawa, K. Tadanaga, A. Hayashi, M. Tatsumisago Solid State Ion. 2011, 192, 185-187.

[31] C. Simari, C. Lo Vecchio, A. Enotiadis, M. Davoli, V. Baglio, I. Nicotera J. Appl. Polym. Sci. 2019, $136,10$.

[32] R. Pizzoferrato, E. Ciotta, I. V. Ferrari, M. Braglia, P. G. Medaglia, A. Mattoccia, L. Di Giamberardino, M. Richetta, P. Knauth, M. L. Di Vona Solid State Ion. 2018, 314, 30-35.

[33] M. L. Di Vona, M. Casciola, A. Donnadio, M. Nocchetti, L. Pasquini, R. Narducci, P. Knauth Int. J. Hydrog. Energy. 2017, 42, 3197-3205.

[34] R. Pizzoferrato, E. Ciotta, I. V. Ferrari, R. Narducci, L. Pasquini, A. Varone, M. Richetta, S. Antonaroli, M. Braglia, P. Knauth, M. L. Di Vona ChemElectroChem. 2018, 5, 2781-2788.

[35] R. Narducci, J. F. Chailan, A. Fahs, L. Pasquini, M. L. Di Vona, P. Knauth J Polym Sci Polym Phys. 2016, 54, 1180-1187.

[36] E. Sgreccia, J. F. Chailan, M. Khadhraoui, M. L. Di Vona, P. Knauth J. Power Sources. 2010, $195,7770-7775$.

[37] M. Braglia, I. V. Ferrari, L. Pasquini, T. Djenizian, M. Sette, M. L. Di Vona, P. Knauth Electrochim. Acta. 2018, 265, 78-88.

[38] L. Pasquini, M. L. Di Vona, P. Knauth New J Chem. 2016, 40, 3671-3676.

[39] J. M. Oh, S. H. Hwang, J. H. Choy Solid State Ion. 2002, 151, 285-291.

[40] F. M. Labajos, V. Rives, M. A. Ulibarri J. Mater. Sci. 1992, 27, 1546-1552.

[41] G. F. L. Ehlers, K. R. Fisch, W. R. Powell J Polym Sci A Polym Chem. 1969, 7, 2931-2953.

[42] T. Kameda, Y. Fubasami, N. Uchiyama, T. Yoshioka Thermochim. Acta. 2010, 499, 106-110.

[43] F. L. Theiss, G. A. Ayoko, R. L. Frost J Therm Anal Calorim. 2013, 112, 649-657.

[44] M. A. Aramendia, Y. Aviles, V. Borau, J. M. Luque, J. M. Marinas, J. R. Ruiz, F. J. Urbano J. Mater. Chem. 1999, 9, 1603-1607.

[45] K. Ohno, M. Okimura, N. Akai, Y. Katsumoto PHYS CHEM. CHEM PHYS. 2005, 7, 3005-3014.

[46] S. Maurya, S. H. Shin, M. K. Kim, S. H. Yun, S. H. Moon J. Membr. Sci. 2013, 443, 28-35.

[47] J. T. Kloprogge, R. L. Frost J. Solid State Chem. 1999, 146, 506-515.

[48] H. A. Miller, J. Ruggeri, A. Marchionni, M. Bellini, M. V. Pagliaro, C. Bartoli, A. Pucci, E. Passaglia, F. Vizza Energies. 2018, 11.

[49] N. g. B. Allou, P. Bordoloi, R. L. Goswamee J. Appl. Polym. Sci. 2017, 134.

[50] A. Filpi, M. Boccia, A. Pucci, F. Ciardelli E-POLYMERS. 2013, 13. 


\section{Table of Contents Graphic}

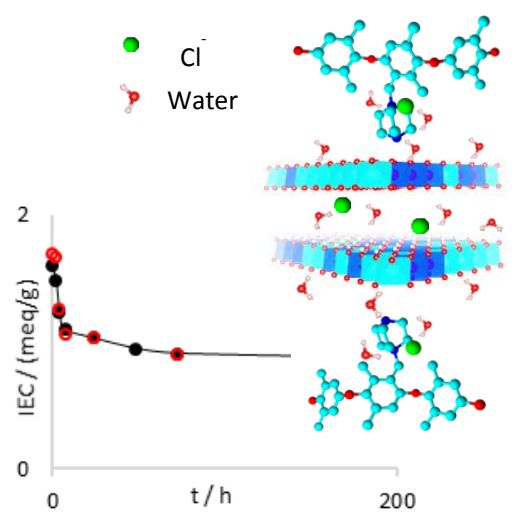

Composite anion exchange membranes made of a chemically resistant polymer backbone poly(phenylene oxide) (PPO), a stiff and bulky functionalizing amine (DABCO) and an anion conducting layered double hydroxide (LDH) as filler are a promising combination to reduce the instability in alkaline solution. The degradation kinetics is followed by measurements of the ionic conductivity, the ion exchange capacity and the water uptake. Its mechanism is studied by thermogravimetric analysis and FTIR spectroscopy. 